\title{
Turbulent Flow Around Circular Arcs
}

\section{Jean-Baptiste R. G. Souppez ${ }^{1,2}$, Patrick Bot $^{3}$ and Ignazio Maria Viola ${ }^{1}$}

\section{AFFILIATIONS}

${ }^{1}$ School of Engineering, Institute for Energy Systems, University of Edinburgh, Edinburgh, UK.

${ }^{2}$ Mechanical, Biomedical and Design Engineering Department, School of Engineering and Technology, College of Engineering and Physical Sciences, Aston University, Birmingham, UK.

${ }^{3}$ Naval Academy Research Institute, Brest, France.

\section{ABSTRACT}

The flow around a circular arc is governed by the effect of the sharp leading edge and by the arc's curvature. There is a range of incidences where a leading-edge separation bubble (LESB) is formed on the convex side of the arc, and the reattached boundary layer separates further downstream. Akin to foils and cylinders, for increasing values of the Reynolds number, the boundary layer turns from laminar to turbulent resulting in a step change in the forces, here termed force crisis. This phenomenon is characterised experimentally for an arc with a camberto-chord ratio of 0.22 and for a range of the Reynolds number from 53,530 to 218,000. Forces are measured both in a towing tank and in a water tunnel, and particle image velocimetry is undertaken in the water tunnel. In stark contrast to cylinders, where the force crisis is associated with laminar-to-turbulent transition of the boundary layer, here it is found to be associated with the suppressed relaminarisation of the boundary layer. In fact, the LESB is always turbulent at the tested conditions, and relaminarisation occurs up to a combination of critical angles of attack and critical Reynolds numbers. The critical angle of attack varies linearly with the Reynolds number. These results may contribute to the design of thin cambered wings, sails and blades at a transitional Reynolds number, such as the wings of micro aerial vehicles, swept wings in subsonic flight, turbomachinery blades and the sails of autonomous sailing vessels.

\section{INTRODUCTION}

Simplified wing geometries, such as that of a circular arc, have been studied for applications at low to moderate Reynolds number $(R e) .^{1-4}$ The flow around a circular arc bears many similarities to that around a circular cylinder, 5,6 although it is comparatively less characterised. A key common feature is, for example, the drag crisis, where the curve of the drag coefficient versus the $R e$ shows a local minimum. For a circular cylinder, the abrupt drop of the drag curve is associated with the laminar-to-turbulent transition of the boundary layer. In fact, the turbulent boundary layer is more resilient to separation, which occurs further downstream compared to a laminar boundary layer. ${ }^{7,8}$ Schewe $^{9-11}$ characterised the flow around a circular cylinder as: (i) subcritical, with laminar separation and transition in the wake; (ii) supercritical, with laminar separation and turbulent reattachment, forming a laminar separation bubble (LSB); and (iii) transcritical, with transition in the boundary layer followed by turbulent separation.

Akin to thin foils, ${ }^{12,13}$ the circular arc can feature both a lift and a drag crisis. This phenomenon, referred to as a force crisis, has been studied for a circular arc at zero angle of attack. ${ }^{14-16}$ Here the angle of attack $\alpha$ is defined as the angle between the chord and the free stream velocity. These studies indicated a noticeable change in the lift sign from negative to positive for values of $R e$ lower and higher than $200,000 \pm 4,000$ respectively. The underlying mechanism of this force crisis at $\alpha=0^{\circ}$ is the same as that of a circular cylinder, i.e. that the boundary layer becomes turbulent at high $R e$ delaying trailing-edge separation. Whilst the flow conditions at which the force crisis occurs and the underlying mechanism are well-established on circular cylinders, ${ }^{17,18}$ these are not so readily available for circular arcs. For example, whether the force crisis is also due to laminar-to-turbulent transition of the boundary layer at high angles of attack is not known.

The flow around a circular arc also bears similarities with that of foils with a sharp leading edge. For small incidences above the ideal angle of attack, i.e. where the stagnation point is at the leading-edge, a leading-edge separation bubble (LESB) is formed on the suction side of the arc. This feature is also known as a thinaerofoil bubble ${ }^{19}$ or nose separation. ${ }^{20}$ Research interest in the
LESB arose significantly from the 1950s onwards due to the greater use of thin aerofoils to reduce compressibility effects as fligh speeds increased. ${ }^{21,22}$ By studying flat plates, Ota et al..$^{23}$ identified three possible behaviours for low, intermediate and high $R e$ : (i) laminar separation with laminar reattachment; (ii) lamina separation with turbulent reattachment; and (iii) turbulent separation with turbulent reattachment.

At intermediate and high $R e$ (by Ota's definition), a turbulent boundary layer develops downstream of the LESB. Hence, at these $R e$ conditions, a force crisis is unexpected. In contrast though, $\mathrm{Bot}^{24}$ reported a force crisis at higher angles of attack than the ideal one, at $R e$ as high as 68,200 . At these conditions a LESB with turbulent reattachment certainly occurs. ${ }^{19}$ The nature of this force crisis, therefore, is yet to be ascertained.

A force crisis could be due to relaminarisation of the boundary layer. Relaminarisation downstream of the LESB is of particula importance to the performance of swept wings. ${ }^{25}$ This was first suggested by Thompson, ${ }^{26}$ and later investigated by Arnal and Juillen $^{27}$ and Van Dam et al.. ${ }^{28}$ Further developments were prompted by new applications in turbomachinery, ${ }^{29}$ micro aeria vehicles $^{3}$ and yacht sails. ${ }^{30}$ For example, relaminarisation following the LESB is desirable in turbomachinery because it results in a lower friction drag. ${ }^{31-33}$

The main aim of this paper is to characterise the flow field around a circular arc through the identification of $\alpha$ and $R e$ resulting in either a subcritical or transcritical flow regime. In the latter case, it is investigated whether the transition occurs within the LESB or the boundary layer, and whether a turbulent LESB might be followed by a relaminarised boundary layer.

The remainder of the paper is structured as follows. Section II introduces the experimental setup, including the geometry and the two facilities, where tests were undertaken. Section III provides a validation of the experimental setup and force measurement results against published data, together with a blockage correction. Then, results are detailed in Section IV, presenting both forces and flow fields. Lastly, Section V summarises the key findings. 


\section{EXPERIMENTAL SETUP}

\section{A. Geometry}

Three circular arcs with a sharp leading edge and the same camber-to-chord ratio, $y_{c} / c=0.2232$, as those tested by Velychko $^{34}$ and Bot $^{24}$ are considered. Figure 1 and Table 1 summarise their main geometric characteristics.

The arcs were made of carbon fibre prepreg (using a female mould tool), which allows sufficient strength and stiffness to adopt a small thickness of $1.8 \mathrm{~mm}$ for the three arcs. The thickness-tochord ratio is smaller than half of that in previous studies by Velychko, ${ }^{34}$ Flay et al. ${ }^{35}$ and Bot,${ }^{24}$ where $t / c$ was between 0.0357 and 0.0400 . The surface of the arcs were sanded down to a smooth finish using 2500 grit wet and dry sandpaper, having a median grain size of $8.4 \pm 0.5 \mu \mathrm{m}$, as defined by the ISO6344-1:1998. ${ }^{36}$ This exceeds the experimental guidelines to ensure a hydrodynamically smooth surface..$^{37}$

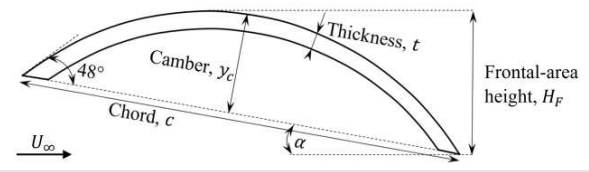

Fig. 1. Experimental geometry

Table 1. Geometric definition of the three circular arcs employed.

\begin{tabular}{lccc}
\hline \hline Circular Arc & $\begin{array}{c}\text { Small } \\
\text { arc }\end{array}$ & $\begin{array}{c}\text { Medium } \\
\text { arc }\end{array}$ & $\begin{array}{c}\text { Large } \\
\text { arc }\end{array}$ \\
\hline Chord, $c(\mathrm{~mm})$ & 100 & 150 & 200 \\
Span, $s(\mathrm{~mm})$ & 370 & 370 & 370 \\
$\begin{array}{l}\text { Aspect ratio (without } \\
\text { considering end plates) }\end{array}$ & 3.70 & 2.47 & 1.85 \\
$\begin{array}{l}\text { Camber, } y_{c}(\mathrm{~mm}) \\
\text { Camber-to-chord ratio, } y_{c} / c\end{array}$ & 22.32 & 33.48 & 44.64 \\
$\begin{array}{l}\text { Radius of curvature of the } \\
\text { external surface, } r(\mathrm{~mm})\end{array}$ & 67.16 & 100.75 & 134.33 \\
$\begin{array}{l}\text { Leading-edge and trailing- } \\
\text { edge angles }\left({ }^{\circ}\right)\end{array}$ & 48 & 48 & 48 \\
$\begin{array}{l}\text { Thickness, } t(\mathrm{~mm}) \\
\text { Thickness-to-chord ratio, } t / c\end{array}$ & 0.0180 & 0.0120 & 0.0090 \\
\hline \hline
\end{tabular}

It is noted that, at $\alpha=0^{\circ}$, the frontal-area height is $H_{F}=y_{c}$. For the incidences covered in this paper, namely $0^{\circ}<\alpha \leq 30^{\circ}, H_{F}$ can be expressed as a function of the radius of curvature of the external surface of the arc, $r$, as

$$
H_{F}=r-\left(\frac{r-y_{c}}{\tan \alpha}-\frac{c}{2}\right) \sin \alpha .
$$

\section{B. Towing tank}

Force measurements were undertaken in the towing tank at Solent University, which has a length of $60 \mathrm{~m}$, width of $3.7 \mathrm{~m}$, depth of $1.8 \mathrm{~m} .{ }^{38}$ All three arcs were tested. Each arc was placed in the centre between the tank's side walls, with the spanwise axis vertical, and the top end-plate $100 \mathrm{~mm}$ below the free surface as shown in Figure 2. A range of Re matching and complementing those tested by previous authors on arcs with the same $y_{c} / c$ was chosen. The small arc was tested at $R e=53,530$ (as in Velychko) $^{34}$ and $R e=68,200$ (as in Bot) ${ }^{24}$, the large arc at $R e=218,000$ (as in Bot $)^{24}$, and the medium arc at $R e=150,000$. The latter value was arbitrarily chosen to provide intermediate data. The circular arc was fitted between $340 \mathrm{~mm}$ long by $340 \mathrm{~mm}$ wide end plates to model an infinite aspect ratio. The test rig was connected to a single-post dynamometer equipped with potentiometers having an accuracy of $\pm 0.001 \mathrm{~N}$. The lift and drag were recorded at $1000 \mathrm{~Hz}$ for six seconds (limited by the run length). The data acquisition was automatically triggered after the desired test speed was reached. The measured data was checked to ensure that no initial transient data was present. The forces created by the test rig, including end plates, were measured by testing without the arc at the various test speeds. These were first time-averaged and then subtracted from the total time-averaged force measurements, to yield the lift $(L)$ and drag $(D)$ of the arc. The uncertainty is quantified in Sec. III A. Lift and drag coefficients are computed as

$$
\begin{aligned}
& C_{L}=\frac{L}{\frac{1}{2} \rho \operatorname{cs} U_{\infty}^{2}}, \\
& C_{D}=\frac{D}{\frac{1}{2} \rho \operatorname{cs} U_{\infty}^{2}},
\end{aligned}
$$

where the density of the water $\rho=998.33 \mathrm{~kg} . \mathrm{m}^{-3}$ is assumed ${ }^{39}$ for fresh water at a measured temperature of $19.4^{\circ} \mathrm{C}, c$ is the chord, $s$ is the span and $U_{\infty}$ is the carriage's velocity.
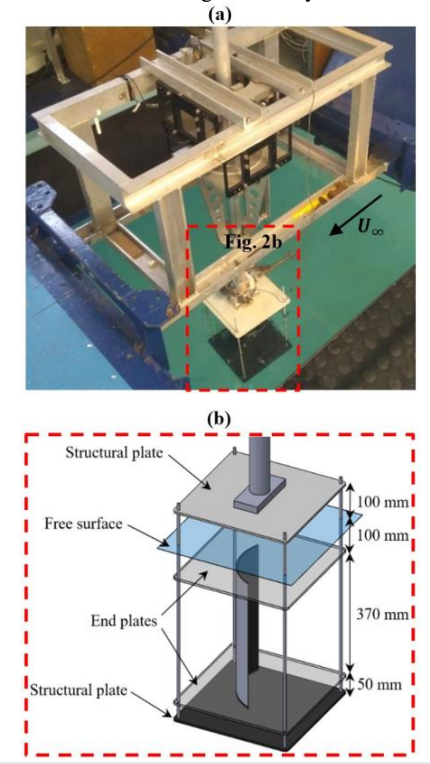

Fig. 2. Towing tank (a) experimental setup and (b) schematic test rig.

\section{Water tunnel}

The $8 \mathrm{~m}$ long water tunnel features a width of $0.4 \mathrm{~m}$, a depth of $0.9 \mathrm{~m},{ }^{40}$ with a water level at $0.34 \mathrm{~m}$. The $c=200 \mathrm{~mm}$ arc was tested at $U_{\infty}=0.347 \mathrm{~m} . \mathrm{s}^{-1}$, i.e. $R e=68,200$. The arc was vertically centred on the water column, with the suction side towards the free surface (blockage effect is discussed in Sec. III B). The circular arc spanned horizontally across the water tunnel's width with a gap of $6 \mathrm{~mm}$ either side to avoid contact. Forces were measured with a six-axis force/torque sensor (Nano 17 IP68 from ATI Inc.) with a resolution of $1 / 160 \mathrm{~N}$. For each tested condition, forces were recorded at $100 \mathrm{~Hz}$ for 45 seconds. Similarly to the towing tank experiments, tests were repeated with and without the arc attached 
to the rig, and the lift and drag of the arc were achieved by the difference of the two time-averaged force measurements. Force coefficients are computed as in Equation 2 and 3, where $\rho$ is the same as in the towing tank, and $U_{\infty}$ is computed as follow. Tests were performed with an empty tunnel (without model and rig) at the same impeller power as the test with the model. The nominal velocity $U_{\infty}$ is taken as the time-averaged streamwise speed measured with a laser doppler anemometer, which also measured the turbulence intensity (TI) as 0.0363 at mid-depth. The streamwise flow velocity in this facility is known to be uniform within $\pm 0.00568 U_{\infty}$ (one standard deviation), in the central $350 \mathrm{~mm}$ of the spanwise test section. ${ }^{41}$

\section{Particle image velocimetry}

A $200 \mathrm{~mJ}$ Nd:YAG pulsed laser at a wave length of $532 \mathrm{~nm}$ was used to illuminate silver coated hollow glass spheres, with a nominal $14 \mu \mathrm{m}$ diameter and specific gravity of 1.7 . The laser sheet had a thickness of approximately $2 \mathrm{~mm}$ and was directed parallel to the onset flow, illuminating the upper (suction) surface of the arc. The experimental setup is shown in Figure 3. Because the focus of the paper is the flow on the suction side of the arc (LESB and trailing-edge separation), no flow visualisation was undertaken on the pressure side of the arc. The only exception was to locate the leading-edge stagnation point (see Sec. IV A). To let the laser sheet illuminate the pressure side, the arc was tested upside down. No measures to counteract reflection (such as rhodamine B coating) appeared necessary thanks to the matt black carbon fibre. The model appeared not to vibrate during the tests. This was confirmed by checking the consistent location of the trailing-edge of the arc with a chord of $200 \mathrm{~mm}$ over 100 images. The streamwise variations never exceed $\pm 2.5 \mathrm{px} \quad(0.268 \mathrm{~mm})$, while the streamnormal variations never exceed $\pm 1.5 \mathrm{px}(0.161 \mathrm{~mm})$.

For each tested condition, 100 pairs of 2056 px by 2060 px images were recorded at $7.5 \mathrm{~Hz}$. A multi-pass (decreasing size) cross-correlation was adopted, with two initial passes having a $96 \mathrm{px}$ by $96 \mathrm{px}$ interrogation window and $50 \%$ overlap, before a final $36 \mathrm{px}$ by $36 \mathrm{px}$ pass with a $75 \%$ overlap. Two fields of view were measured: a wide view of $224 \mathrm{~mm}$ by $224 \mathrm{~mm}$ including the whole arc, and a zoomed-in view of the leading edge of $32 \mathrm{~mm}$ by $32 \mathrm{~mm}$. These yield velocity fields with a spatial resolution of $0.872 \mathrm{~mm}(0.00436 c)$ and $0.125 \mathrm{~mm}(0.000625 c)$, respectively.

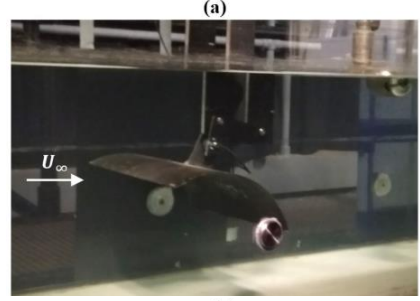

(b)

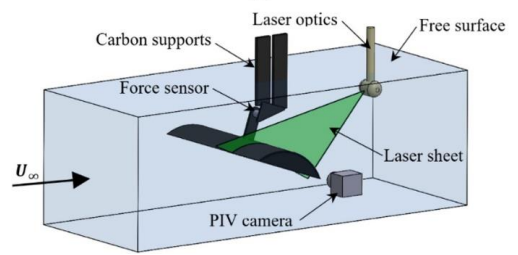

Fig. 3. Water tunnel (a) experimental setup and (b) schematic test
The uncertainty inherent to the particle image velocimetry (PIV) measurements is based on both bias and error, the former being know and constant, the latter requiring estimation. ${ }^{42}$ The bias for the water tunnel employed is \pm 0.015 pixels based on the PIV measurements of random error previous undertaken. ${ }^{41}$ The error associated with the present experimental setup can be estimated as up to \pm 0.03 pixels based on the experimental setup described above and the computed values of the correlation peak. ${ }^{43}$ This yields a pixel displacement measurement uncertainty of \pm 0.045 pixels, corresponding to a velocity uncertainty of $\pm 0.0157 U_{\infty}$.

\section{VALIDATION OF THE EXPERIMENTAL} SETUP

\section{A. Force measurements}

Towing tank tests at $R e=53,530$ are compared with the wind tunnel tests undertaken by Velychko ${ }^{34}$ on an arc with $y_{c} / c=0.2232$ and $t / c=0.0357$ at the same $R e$. The aspect ratio $(A R)$ of the arc in the towing tank is 1.85 and it is equipped with end plates, while the arc tested by Velychko ${ }^{34}$ in the wind tunnel has $A R=10$ and it spans across the whole tunnel with the top and bottom walls acting as end plates. The comparison is presented in Figure 4, with error bars corresponding to one standard deviation for the sampled data These will be omitted in subsequent figures for clarity. The agreement suggests that the end plates used in the towing tank are effective in reproducing an arc with an infinite aspect ratio. Furthermore, because the thickness-to-chord ratios of 0.0357 and 0.0180 provide similar results, the thickness effect is considered to be negligible.
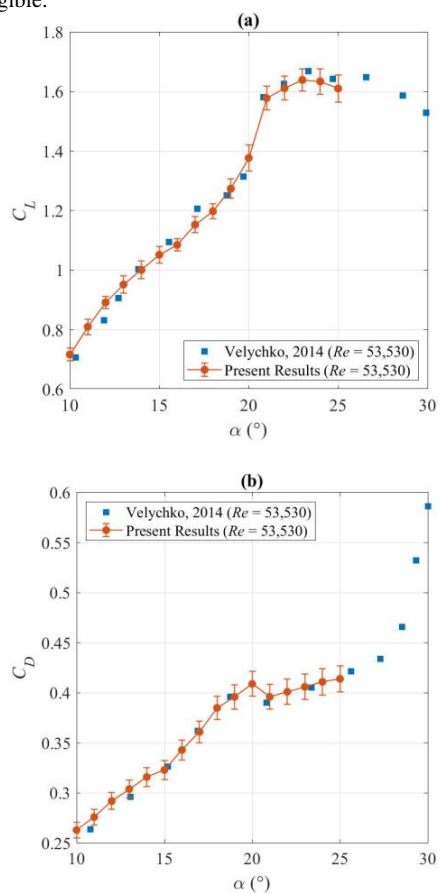

Fig. 4. Lift (a) and drag (b) coefficients versus the angle of attack measured in the towing tank on the large arc at $R e=53,530$, and comparison with the wind tunnel data by Velychko. ${ }^{34}$ 


\section{B. Blockage correction}

In the water tunnel, the arc is comparatively large relative to the test section. The ratio between the frontal area of the model and the area of the test section exceeds the recommended maximum values of $0.10-0.15 .^{44-45}$ The relatively large model was chosen to achieve low geometric uncertainty and high spatial PIV resolution. Hence, to ensure the blockage effect was correctly accounted for, a new set of experiments was undertaken in the towing tank to investigate the blockage effect. In this instance, blockage comprises solid blockage, wake blockage, and the blockage effect on the streamline curvature. ${ }^{44}$

The arc was enclosed between two vertical plates mimicking the effect of the bottom and the top surface of the water tunnel. These side plates, which were $1200 \mathrm{~mm}$ long by $1200 \mathrm{~mm}$ tall, and extended $3 c$ upstream and $2 c$ downstream, were separated by a transverse distance $d=340 \mathrm{~mm}, 550 \mathrm{~mm}$ and $1180 \mathrm{~mm}$, as shown in Figure 5. Measurements were also taken without side plates, where the towing tank side walls acted as plates at a distance of $3700 \mathrm{~mm}$. The distance $d=340 \mathrm{~mm}$ corresponds to the water depth in the water tunnel. The forces measured in the water tunnel are expected to match those measured with the side plates at $d=340 \mathrm{~mm}$ in the towing tank. These tests were performed at $R e=68,200,150,000$ and 218,000 , and $\alpha=5^{\circ}, 10^{\circ}, 15^{\circ}$ and $20^{\circ}$.

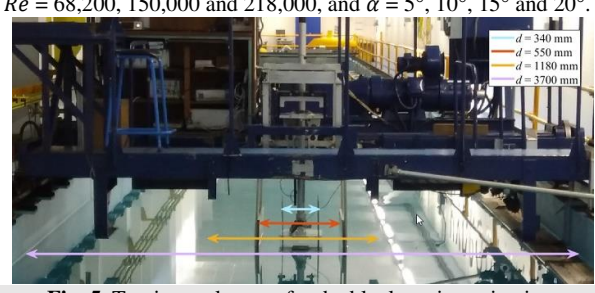

Fig. 5. Towing tank setup for the blockage investigation.

The blockage ratio ${ }^{44}$ is defined as the ratio between the projected frontal area of the arc $A_{F}=H_{F} S$ (where $H_{F}$ varies with $\alpha$, see Equation 1), and the area enclosed by the side plates $A_{S}=d s$. The latter is the area of the rectangle formed by the product of the span of the arc wing and the distance between the plates. For each angle of attack $\alpha$, the blockage ratio is changed by varying the distance $d$ between the side plates, and thus $A_{S}$.

A linear fit of the force coefficient $\left(C_{L B}\right.$ and $C_{D B}$ for lift and drag, respectively) with the blockage ratio is computed by least squares method for each $\alpha$. The intercept with the ordinate, i.e. the value taken by the coefficient for a vanishing blockage, is assumed to be the true coefficient in open flow conditions $\left(C_{L}\right.$ and $C_{D}$ for lift and drag, respectively). Figure 6 shows the ratio of the true lift and drag coefficients $\left(C_{L}\right.$ and $\left.C_{D}\right)$ over the recorded values with blockage $\left(C_{L B}\right.$ and $\left.C_{D B}\right)$ versus the blockage ratio $\left(A_{F} / A_{S}\right)$, for $R e=68,200$.

The highest blockage effect is found for $\alpha=5^{\circ}$, where the slope of the correction is the highest (Fig. 6). At this incidence, $\mathrm{Bot}^{24}$ showed that the stagnation point is on the suction side of the arc, and a large region of recirculating flow occurs on the pressure side of the arc. The blockage seems to affect significantly the forces at this incidence, but the rest of the paper will focus on highest incidences, where the stagnation is at the leading edge or on the pressure side of the arc. At $\alpha \geq 10^{\circ}$, the blockage effect is considerably lower and the linear regression is a good approximation of the measured forces. While not shown for brevity, the linear fit for each $\alpha$ also shows a mild dependency with the Reynolds number.
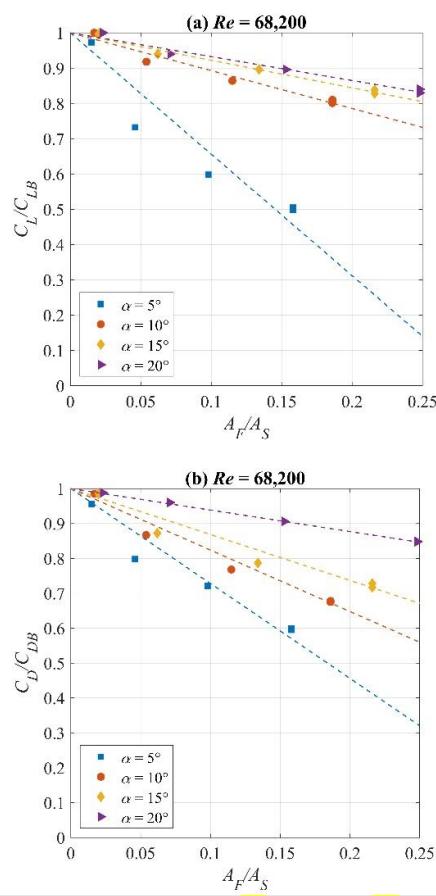

Fig. 6. Ratio of the corrected lift (a) and drag (b) over thei measured values versus the blockage ratio for different angles of attack at $R e=68,200$.

The measured and the corrected lift and drag coefficients are shown in Figures 7 for $R e=68,200$. Blockage is negligible in all towing tank experiments without side plates, because the blockage ratio is $0.0030<A_{F} / A_{S}<0.0047$, whilst it is significant for the water tunnel tests, where $0.1461<A_{F} / A_{S}<0.2477$. The measured data (Fig. 7a and 7b) collapse on one curve when corrected (Fig. 7c and $7 \mathrm{~d}$ ). The corrected lift is on average $1.87 \%$ lower than the unblocked lift for $5^{\circ}<\alpha<17^{\circ}$. At the highest incidences, $\alpha>17$, the lift is on average $3.99 \%$ lower than the unblocked lift. This is attributed to the effect of free surface deformation in the water tunnel. The corrected drag is on average $1.10 \%$ lower than the unblocked drag.

Forces were also measured in the water tunnel with a solid top plate restricting any free surface deformation. As such, this setup is most similar to the towing tank experiment. When the top plate is present, the corrected lift coefficient measured in the water tunnel collapses on that measured in the towing tank.

A key finding is that the effect of blockage does not alter the angle of attack at which the lift and drag crisis occur, namely $\alpha=15^{\circ}$ in Figure $7(R e=68,200)$. This demonstrates that the critical angle of attack can be correctly identified even for a large blockage ratio (at least within the range considered in this work, namely in excess of 0.20 ). This also justifies using differen blockage corrections for every angle of attack and Reynolds number, because the flow regime (subcritical or transcritical) does not vary with the blockage ratio. 

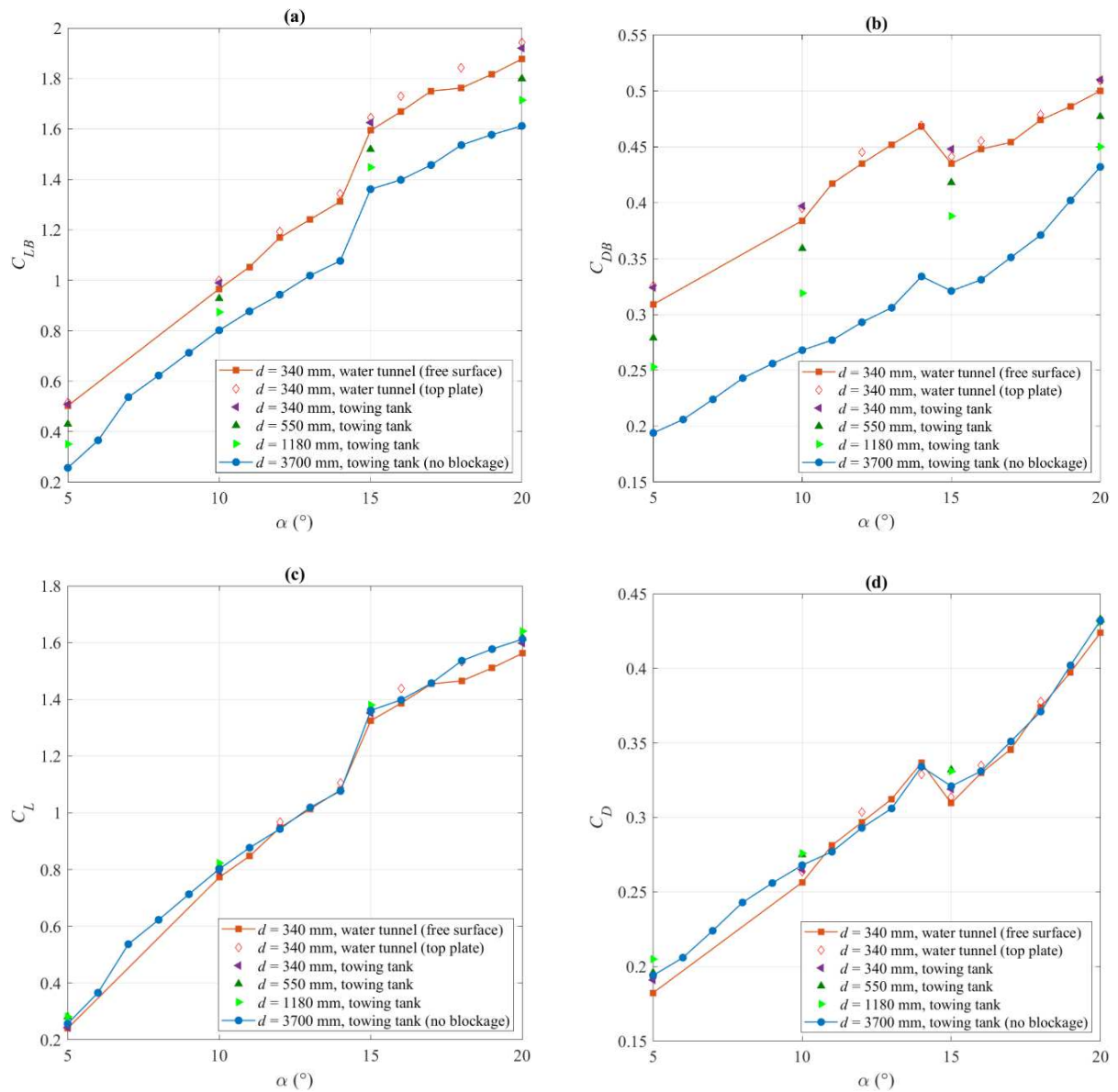

Fig. 7. Measured lift (a) and drag (b) coefficients and corrected lift (c) and drag (d) coefficients at $R e=68,200$. Sub-figures (c) and (d) include standard low-speed wind tunnel blockage correction. ${ }^{44}$

\section{RESULTS}

\section{A. Force crisis}

The lift and the drag crisis are shown in Figure 8 for a range of $R e$. First, consider the only curve not showing the force crisis in the tested range of $\alpha$. At the highest $R e$ of 218,000, the force crisis occurs at $\alpha<0^{\circ}$. In fact, Bot et al. ${ }^{14}$ found that the force crisis occurs at $\alpha=0^{\circ}$ for $R e=200,000 \pm 4,000$, and that turbulent trailing-edge separation occurs on the suction side of the arc. The drop in lift at $\alpha=9^{\circ}$ was incorrectly attributed to the occurrence of LESB. ${ }^{46}$ The analysis of the stagnation point shown in Figure 9, however, reveals that this is not the case, because the ideal angle of attack above which the LESB occurs is $11^{\circ}$. Here, it is assumed that, within the same flow regime (subcritical or transcritical), since the lift does not vary significantly with $R e$, the stagnation point remains in the same position. The local minimum of the lift is between $\alpha=8^{\circ}$ and $10^{\circ}$. This is because of the following. As $\alpha$ increases, the point of trailing-edge separation moves upstream and so the force tends to decrease. On the other hand, as $\alpha$ increases, the frontal projected area increases and so the force tends to increase. For $8^{\circ}<\alpha<9^{\circ}$, the first effect dominates. For $\alpha>9^{\circ}$, the latter effect dominates. 

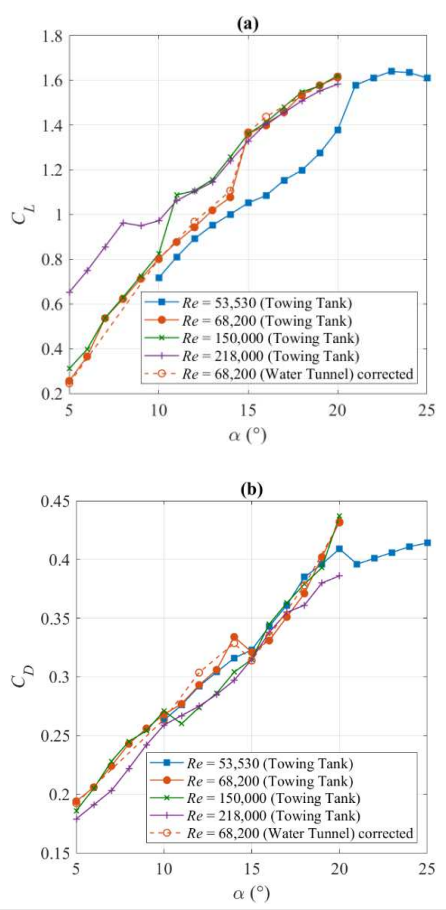

Fig. 8. Lift (a) and drag (b) coefficients versus angle of attack for the range of investigated Reynolds numbers.

The ideal angle of attack is the angle of incidence where the stagnation point is at the leading edge. This is identified as the location where the tangential velocity at the closest measurement point to the wall vanishes. ${ }^{47}$ To increase the accuracy of this measurement, the field of view is zoomed to the leading edge.

Figure 9 shows the location of the stagnation point around the leading edge of the plate for $\alpha$ from $8^{\circ}$ to $12^{\circ}$ at $R e=68,200$. These were obtained with the zoomed-in field of view described in Sec. II D. The results are consistent with the flow visualisation of Martin, ${ }^{48}$ who identified a LESB from $\alpha \geq 12^{\circ}$ on an identical geometry.

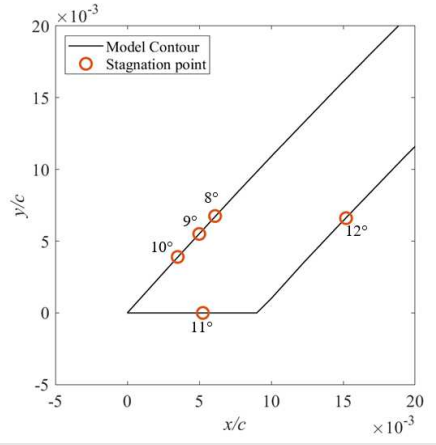

Fig. 9. Location of the stagnation near the leading edge for different of angles of attack at $R e=68,200$.
Returning to Figure 8, two trends can be observed: a low- $R e$ trend marked by the curve at $R e=53,530$ (up to $\alpha=20^{\circ}$ ), and high- $R e$ trend marked by the curve at $R e=218,000$. All othe curves for intermediate $R e$ follow the low- $R e$ trend up to the force crisis, and then follow the high- $R e$ trend. In other words, for any angle of attack, the lift and the drag can only take either a low-Re value, or a high- $R e$ value. This is better visualised in Figure 10 (a), which shows that for a constant $\alpha=11^{\circ}$, both the lift and drag coefficients do not vary significantly with $R e$ but for the force crisis, which occurs at $R e=144,000 \pm 2,000$. Indeed, Figure 10 (a) highlights the existence of a critical $R e$, at which the force crisis occurs for a given $\alpha$. Now, consider the critical angle of attack at which the force crisis occurs for a given $R e$. This is shown in Figure $10(\mathrm{~b})$, where the lift and drag coefficients are plotted versus $\alpha$ for $R e=150,000$
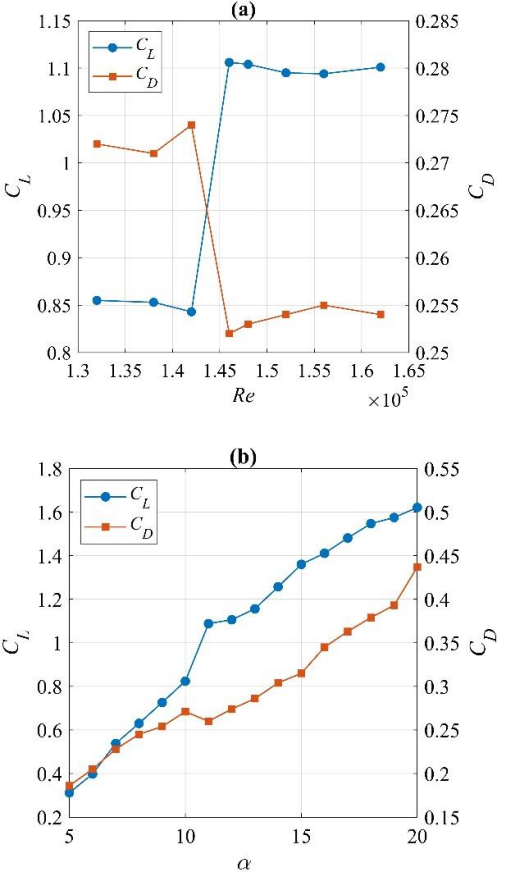

Fig. 10. Lift and drag coefficient (a) versus $R e$ for $\alpha=11^{\circ}$, and (b) versus the angle of attack for $R e=150,000$.

The relationship between the critical $R e$ and the critical $\alpha$ appears to be linear. As shown in Figure 11, where horizontal error bars show the uncertainty in the estimate of the critical $R e$ at a given angle of attack; for instance at $\alpha=11^{\circ}$, the critical Re occurs between 142,000 and 146,000. Conversely, vertical error bars depict the uncertainty in the estimate of the critical $\alpha$ for a given Reynolds number; e.g. at $R e=68,200$, the critical $\alpha$ is between $14^{\circ}$ and $15^{\circ}$ 


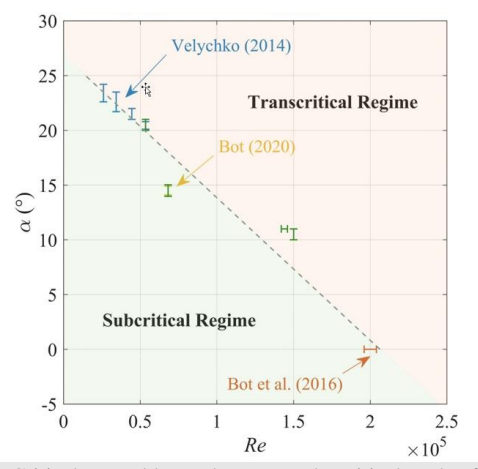

Fig. 11. Critical Reynolds number versus the critical angle of attack at which the force crisis occurs. Results from the present study are show in green. The plot also shows data from Velychko ${ }^{34}$ at $R e=53,530,44,500,34,300$ and 26,015; Bot et al..$^{14}$ at $\alpha=0^{\circ}$, and $\mathrm{Bot}^{24}$ at $R e=68,200$. At $R e=53,530$ and 68,200, the present data overlap that of Velychko ${ }^{34}$ and Bot, ${ }^{24}$ respectively.

\section{B. Trailing-edge separation}

As for a circular cylinder, the force crisis of the arc is associated with a step shift of the trailing-edge separation point. This is pictured in Figure 12, where the nondimensional chordwise coordinate of the trailing-edge separation point, $x_{s} / c$, is plotted versus $\alpha$ for $R e=68,200$. The separation point is identified using definition as in Section IV A. ${ }^{44}$ Upstream of this point, the tangential velocity is positive streamwise, and vice versa downstream. Based on the PIV uncertainty (Sec. II D), the uncertainty related to the position of $x_{s} / c$ in the time-averaged flow field is lower than the spatial resolution, i.e. $0.00436 c$.

For increasing $\alpha$, the trailing-edge separation point occurs more and more upstream. However, there is a critical $\alpha$, which is between $14^{\circ}$ and $15^{\circ}$ for $R e=68,200$, at which the trailing-edge separation point jumps downstream for a small increment of $\alpha$. A similar behaviour of the trailing edge separation point has been shown to underpin the force crisis on foils. ${ }^{13}$

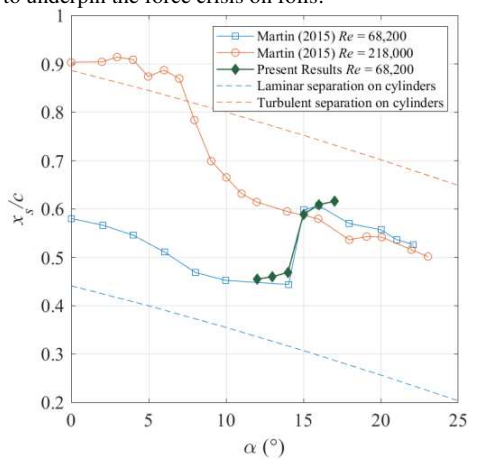

Fig. 12. Nondimensional chordwise coordinate of the trailing-edge separation point versus the angle of attack. Data by Martin ${ }^{48}$ for an arc with the same camber-to-chord ratio at $R e=68,200$ and 218,000 , as well as the equivalent separation point for a circular cylinder, as illustrated in Figure 13.

Figure 12 also includes the coordinate of the trailing-edge separation point measured by Martin ${ }^{48}$ at $R e=68,200$ and 218,000.
Firstly, it can be observed that the present data at $R e=68,200$ is consistent with that measured by $\operatorname{Martin}^{48}$ at the same $R e$. Secondly, it is noted that the location of the separation point is similar for $R e=68,200$ and $R e=218,000$ in the transcritical regime (i.e. $\alpha>15^{\circ}$ for $R e=68,200$ ).

Figure 12 also shows the equivalent laminar and turbulent separation points for a cylinder (dashed lines). These values are computed as shown in Figure 13. The separation angle is taken as $82^{\circ}$ for laminar separation $(R e<300,000)$ and $125^{\circ}$ for turbulent separation $(R e>300,000) .{ }^{18}$ These two separation points are mapped onto a circular arc at an angle of incidence $\alpha$, and projected onto the chord line to yield the nondimensional chordwise separation point $x_{s} / c$. The trends of the trailing edge separation coordinate for the cylinder and the arc tested by Martin ${ }^{48}$ are similar at low $\alpha$ and high $\operatorname{Re}(218,000)$. At $\alpha>5^{\circ}-10^{\circ}$, the lift generated by the arc is probably responsible for a higher adverse pressure gradient that results in earlier separation compared to the cylinder. At low $\operatorname{Re}(68,200)$, in the subcritical regime, trailing-edge separation seems to occur comparatively further downstream on the arc than on the cylinder, but the cause of this is not revealed by the present work

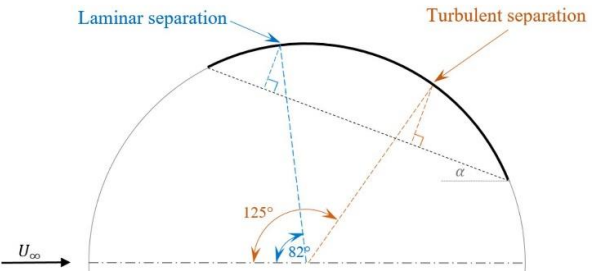

Fig. 13. Schematic representation of the equivalent nondimensional chordwise separation point for a circular arc based on a circular cylinder.

The step shift downstream of the trailing edge separation point is directly associated to a step increase in the lift, and a step decrease in the drag (Fig. 10). In fact, as showed by Viola and Flay ${ }^{49}$ on a thin wing, the more upstream the trailing-edge separation point, the more it results in a smoother suction peak and a lower overall suction, and thus in a lower lift. As the separation point shifts downstream, the suction peak at mid-chord associated with the maximum curvature increases leading to a higher lift. The drag decreases because the wake thickness decreases. ${ }^{50}$ The wake thickness, in fact, is roughly proportional to the distance (measured in the flow-normal direction) from the trailing edge to the separation point, which are the two points from where the separated shear layers are originated.

\section{Laminar or turbulent state of the boundary} layer at the trailing-edge separation point

In Sec. IV A, the subcritical and transcritical regimes were characterised. In Sec. IV B, it was shown that, similar to the circular cylinder, the force crisis is associated with a shift in the trailingedge separation point. In this section the reason underlying this shift is investigated. For the circular cylinder, this is due to the laminar-to-turbulent transition in the boundary layer, such that the point of separation shifts downstream when the separation boundary layer is turbulent instead of laminar.

The most accurate mean to measure the laminar or turbulent state of the boundary layer is to measure the intermittency. ${ }^{51}$ However, this approach requires measuring the flow velocity with 
a time resolution of the order of the smallest turbulent time scale, and such instrumentation is not available to the authors. Alternatively, it is common practice to consider high values of the turbulent kinetic energy as a proxy for turbulent flow.

The turbulent kinetic energy is computed as

$$
\kappa=\frac{1}{2}\left(\overline{\left(u^{\prime}\right)^{2}}+\overline{\left(v^{\prime}\right)^{2}}+\overline{\left(w^{\prime}\right)^{2}}\right),
$$

where $\overline{\left(u^{\prime}\right)^{2}}, \overline{\left(v^{\prime}\right)^{2}}$ and $\overline{\left(w^{\prime}\right)^{2}}$ are the variances of the streamwise, streamnormal and spanwise velocity fluctuations, respectively. The spanwise velocity fluctuation could not be measured with planar PIV and thus was neglected.

For the purpose of this paper, the flow is considered to be turbulent for $\kappa>10^{-2} U_{\infty}^{2}$ to distinguish between the laminar and turbulent state of the flow. This criterion, although not exact, has been proven to be robust over a wide range of flow conditions. In particular, $\kappa$ increases abruptly by one, or more orders of magnitude when transition occurs, and thus the exact value of the threshold is unimportant. For example, Lee et al. ${ }^{52}$ modelled the leading-edge separation bubble of a flat plate with a blunt leading edge at chord-based $R e$ from 5,000 to 20,000, and the laminar separation bubble of a foil at incidence at $R e=30,000$. They showed that $\kappa$ is of the order of $10^{-3} U_{\infty}^{2}$ or lower when the boundary layer is laminar, and greater than approximately $5 \times 10^{-3} U_{\infty}^{2}$ when transition occurs. This threshold, which is half of the one adopted in the paper, is applicable to both the plate and the foil. On the flat plate, for example, the LESB is laminar for $R e=6,100$ and $\kappa$ is of the order of $10^{-3} U_{\infty}^{2}$ or lower, whilst it is turbulent for $R e=11,000$, and $\kappa>5 \times 10^{-3} U_{\infty}^{2}$. Crompton and Barrett ${ }^{53}$ tested a flat plate with a sharp leading edge similar to ours, at $3^{\circ}$ incidence at $R e$ from 53,000 to 218,000 . They measured the root mean square of the velocity, $u_{\mathrm{rms}}$, in the LESB. By using the approximation $u_{\mathrm{rms}} \approx \sqrt{2 \kappa}$, our threshold is equivalent to $u_{\mathrm{rms}} \approx 0.15 U_{\infty}$, which is in excellent agreement with the values that they measured at the transition. The same $u_{\mathrm{rms}}$ values were also computed numerically by Sampaio et al. ${ }^{54}$ who modelled numerically the experiments of Crompton and Barrett. ${ }^{53}$

This threshold is also resilient to different levels of background turbulence. For example, Breuer ${ }^{55}$ tested numerically a foil at $4^{\circ}$ incidence, with a background turbulence intensity from 0 to $11.2 \%$. For $\mathrm{TI}=0 \%, 0.7 \%, 1.4 \%$, and $2.8 \%$, a LSB occurs an transition is well identified by the criterion $\kappa>10^{-2} U_{\infty}^{2}$. For the highest TI of 5.6\% and $11.2 \%$, the boundary layer is turbulent from further upstream, with $\kappa>10^{-2} U_{\infty}^{2}$, and separation is suppressed. This also shows that the criterion applies to both natural (when $\mathrm{TI}=0 \%$ ), and bypass transition (when TI is, for example, $2.8 \%$ ). This is further confirmed by the simulations of Langari and Yang, ${ }^{56}$ who tested a semi-infinite flat plate with a circular leading edge. The Reynolds number based on the plate thickness is 3450 , and they tested both with zero background turbulence and with $\mathrm{TI}=5.6 \%$. At these two conditions, they observed natural and bypass transition in the LSB, respectively, and transition was well identified by the criterion $\kappa>10^{-2} U_{\infty}^{2}$.

Figure 14 shows the filled contours of $\kappa / U_{\infty}^{2}$ as well as isocontours around the arc for $\alpha$ ranging from $12^{\circ}$ to $17^{\circ}$ at $R e=68,200$. Only the regions where $\kappa>10^{-2} U_{\infty}^{2}$ are coloured The contours are computed based on 100 images. In addition, the isocontour $\kappa=10^{-2} U_{\infty}^{2}$ computed with only 80 images is also shown in red in Figure 14 (a). The marginal difference between the isocontours computed with 80 and 100 images suggests that the results are almost independent of the sample size. It is noted that images are taken at a lower frequency than that of the vortex shedding. Based on the oscillations in the lift force measurement for the circular arc, the chord-based Strouhal number is estimated to be $S t \approx 0.109$. Consequently, the vortex shedding frequency, $f$, computed from the Strouhal number, is about $0.18 \mathrm{~Hz}$, which is lower than the sampling frequency $7.5 \mathrm{~Hz}$.

At $R e=68,200$, the force crisis (Fig. 7) and the downstream shift of the trailing-edge separation point (Fig. 12) occurs at $\alpha$ between $14^{\circ}$ and $15^{\circ}$. This is consistent with the contours in Figure 14, where transition occurs in the separated shear layer of the wake for $\alpha \leq 14^{\circ}$, whereas transition takes place in the boundary layer upstream of separation for $\alpha \geq 15^{\circ}$. The trailingedge separation point is indicated by a red diamond. Similarly to the cylinder, separation is laminar in the subcritical regime, and turbulent in the transcritical regime. 

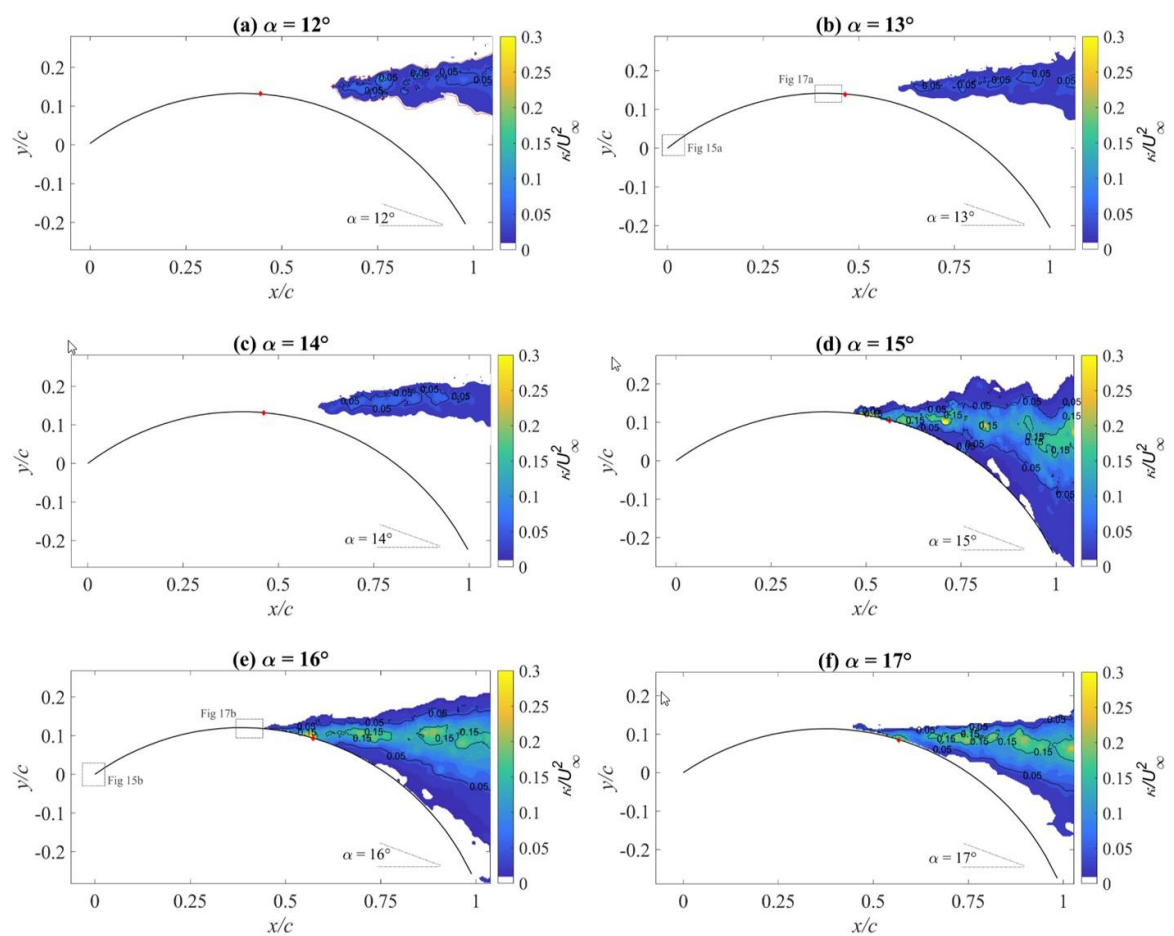

Fig. 14. Contours and isocontours of nondimensional turbulent kinetic energy (plotted for $\kappa>10^{-2} U_{\infty}^{2}$ ) and location of the trailing-edge separation point $(\diamond)$ at $R e=68,200$ and angles of attack from $12^{\circ}$ (a), $13^{\circ}(\mathrm{b}), 14^{\circ}(\mathrm{c}), 15^{\circ}(\mathrm{d}), 16^{\circ}$ (e) and $17^{\circ}$ (f). The isocontours $\kappa=10^{-2}$ $U_{\infty}^{2}$ based on 80 images instead of 100 is depicted by the red line (-) in (a). The zoomed-in field of view used in Figures 15 and 17 are shown in (b) and (e).

\section{Transition to Turbulence and Relaminari- sation}

In the previous sections the flow conditions at which the force crisis occurs (Sec. IV A) have been identified and have been shown to be associated with a shift in the trailing-edge separation point (Sec. IV B). Akin to a circular cylinder, the results allowed to identify that it is also associated with the change in the state of the boundary layer (laminar or turbulent) at the point of trailing-edge separation (Sec. IV C). This section now investigates whether the laminar-to-turbulent transition occurs within the LESB, or within the reattached boundary layer, as for a circular cylinder.

To investigate, this paper focuses on one representative condition for both the subcritical and the transcritical regime, namely $\alpha=13^{\circ}$ and $\alpha=6^{\circ}$ at $R e=68,200$. At these conditions, the LESB is too thin to be measured, but the stagnation point is on the windward (pressure) side of the arc and thus flow separation must occur at the sharp leading edge. At $\alpha=13^{\circ}$, the boundary layer is laminar at the point of trailing edge separation, whilst it is turbulent for $\alpha=16^{\circ}$. However, in Figure 15, where the field of view is zoomed to the leading edge, the $\kappa$ values clearly show that the flow is turbulent near the leading edge in both conditions. The high spatial resolution is shown by the insert in Fig. 15 (a), which would include $15 \times 15$ velocity vectors. For both a lower and higher $R e$ $(53,000$ and 218,000 respectively) than the one tested here, for a flat plate with a similar leading-edge shape at an incidence of $3^{\circ}$, Crompton and Barret ${ }^{51}$ showed that the $\kappa>10^{-2} U_{\infty}^{2}$ threshold is effective in detecting laminar to turbulent transition.

The transition occurs along the shear layer developing from the leading edge but relaminarisation occurs from $x / c \approx 0.02$ in the subcritical regime $\left(\alpha=13^{\circ}\right.$, see Fig. 15a), whilst it remains turbulent in the transcritical condition $\left(\alpha=16^{\circ}\right.$, see Fig. 15b). This is also shown in Figure 16 by the maximum value of $\kappa / U_{\infty}^{2}$ which decays along the streamwise direction for the subcritical regime and vice versa for the transcritical regime.

To verify this result further, the relaminarisation criterion ${ }^{57}$ based on the acceleration parameter $K,^{58}$ is employed, and is computed as

$$
K=\frac{v}{U^{2}} \frac{d u}{d x} \geq 3.5 \times 10^{-6},
$$

where $v$ is the kinematic viscosity and $d u / d x$ is the local streamwise velocity gradient. This criterion is commonly employed to assess relaminarisation in the leading-edge region of turbomachinery blades ${ }^{32}$ and swept wings. ${ }^{28}$ The streamwise velocity gradients vary mildly with the distance from the wall, as shown by Figure 15 (c) and (d) for $\alpha=13^{\circ}$ and $\alpha=16^{\circ}$ respectively. The evaluation of the acceleration parameter downstream of the LESB $(0.02<x / c<0.03)$ for $\alpha=13^{\circ}$ and $16^{\circ}$, respectively yields values of $K=7.87 \times 10^{-5}$ and $K=5.59 \times 10^{-7}$ at $y / c=0.004$ (corresponding to the maximum wall-normal height of 
the LESB), as well as $K=8.68 \times 10^{-5}$ and $K=7.91 \times 10^{-7}$ at $y / c=0.008$ (twice the maximum wall-normal height of the LESB). Therefore, the relaminarisation criterion is satisfied with significant margin for $\alpha=13^{\circ}$, and it is not satisfied for $\alpha=16^{\circ}$. Overall, these results confirm that transition occurs in the leadingedge shear layer and the state of the boundary layer is determined by whether relaminarisation occurs or not.
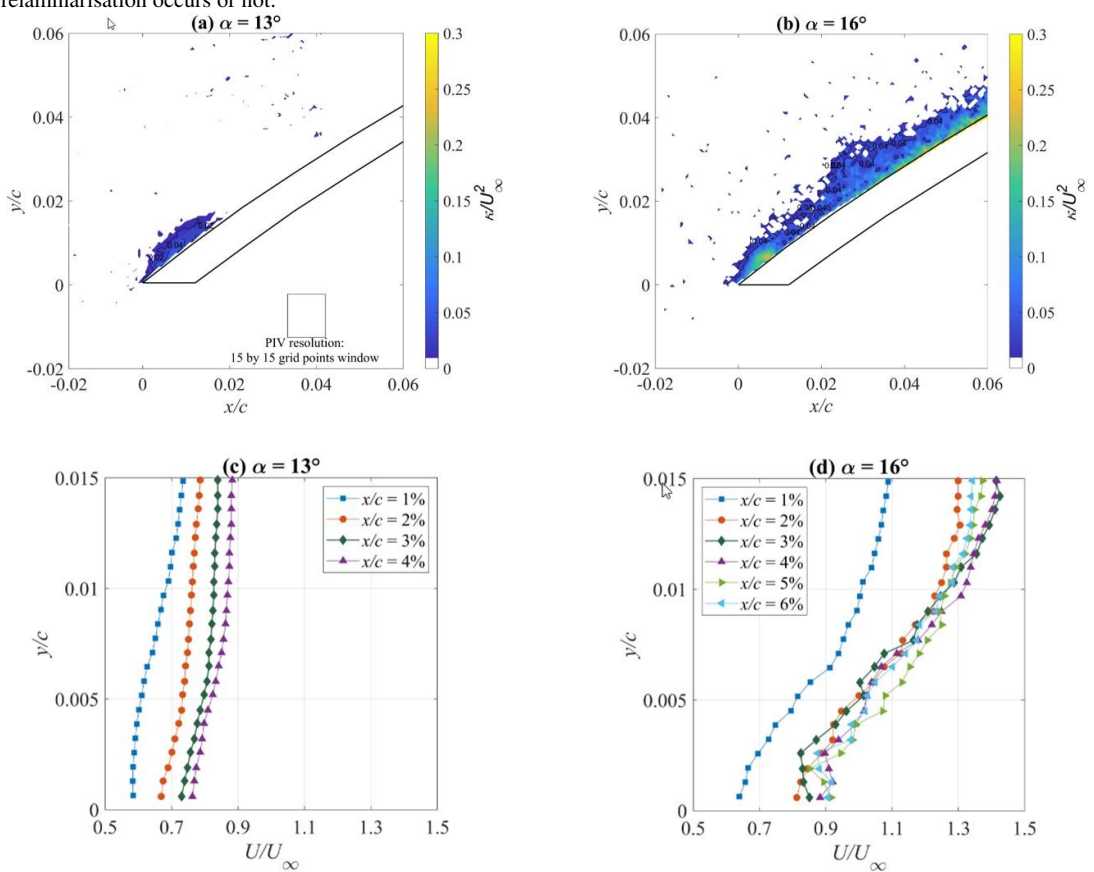

Fig. 15. Contours and isocontours of nondimensional turbulent kinetic energy (plotted for $\kappa>10^{-2} U_{\infty}^{2}$ ) and time-averaged wall-norma profiles of streamwise velocity for various chordwise coordinates near the leading edge at $\alpha=13^{\circ}\left(\mathrm{a}-\mathrm{c}\right.$ ) and $\alpha=16^{\circ}$ (b-d) at $R e=68,200$. The insert in the background of (a) shows a 15 by 15 grid points square for the PIV spatial resolution, namely $0.000625 c=0.125 \mathrm{~mm}$.

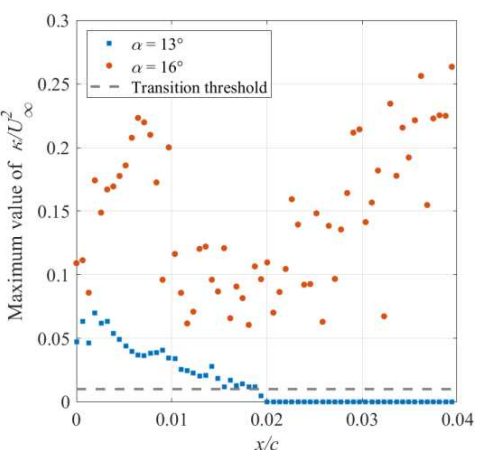

Fig. 16. Maximum values of nondimensional turbulent kinetic energy $\kappa / U_{\infty}^{2}$ at $\alpha=13^{\circ}$ and $\alpha=16^{\circ}$ for $y \leq 0.015 c$ at $R e=68,200$.

The state of the boundary layer does not appear to change any further along the arc. For example, the relaminarised boundary layer at $\alpha-13^{\circ}$ remains laminar all the way to the point of trailing- edge separation. This is consistent with the laminar state of the boundary layer on a circular cylinder at $R e=68,200$. In fact, Zdravkovich ${ }^{18}$ states that the minimum $R e$ for transition to occur in the boundary layer of a circular cylinder is 100,000 . The Reynolds number $R e_{d}$ based on the diameter of a circular cylinder with the same radius of curvature as the arc is $R e_{d}=91,606$, which is thus insufficient to trigger transition in the boundary layer.

If relaminarisation does not occur immediately downstream of the LESB such as for $\alpha=16^{\circ}$, the boundary layer remains turbulent all the way to the separation point. This is shown in Figure 17, where a zoom-in view of the $\kappa / U_{\infty}^{2}$ contrours in the boundary layer immediately upstream of the trailing-edge separation are shown. For the subcritical regime (Fig. 17a), values of $\kappa / U_{\infty}^{2}$ are two orders of magnitude lower than for the transcritical regime (Fig. 17b), demonstrating a laminar boundary layer (note that the colourscale is different between Fig. 17a and 17b). In these conditions, the contours are attributed to the water tunnel background turbulence and to the measurement noise (see PIV uncertainty in Sec. II D). Conversely, in the transcritical regime, the values of $\kappa / U_{\infty}^{2}$ are above the threshold and are of the same 
order of magnitude as at the leading edge (Fig. 15) and in the wake (Fig. 14).
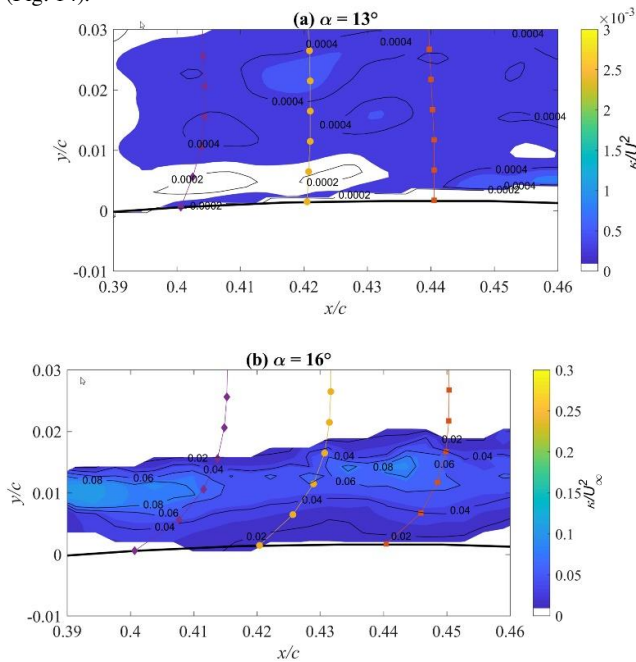

Fig. 17. Contours and isocontours of nondimensional turbulent kinetic energy (plotted for (a) $\kappa>10^{-4} U_{\infty}^{2}$, and (b) $\kappa>10^{-2} U_{\infty}^{2}$ ) and wall-normal profiles of streamwise velocity $\alpha=13^{\circ}$ (a) and $\alpha=16^{\circ}$ (b) at $R e=68,200$. The colour bar in (a) is two orders of magnitude lower than in (b).

Overall, in this section it has been shown that the force crisis on the tested arc is associated with the relaminarisation of the boundary layer at subcritical conditions. This is in contrast with the force crisis on a circular cylinder that is associated with the laminar-to-turbulent transition of the boundary layer at transcritical conditions.

\section{CONCLUSIONS}

Three geometrically similar circular arcs with a camber-tochord ratio of 0.2232 were tested in a towing tank and a water tunnel over a range of Reynolds number spanning from 53,530 to 218,000 . Force measurements were realised in both facilities and particle image velocimetry was undertaken in the water tunnel. Both the lift and the drag curves versus the Reynolds number are known to show an abrupt step change, akin to foils at transitional Reynolds numbers, and to the drag crisis of circular cylinders. Similar to a foil and a circular cylinder, the boundary layer on the suction side of the arc is laminar in the subcritical regime, and is turbulent in the transcritical regime. The separation point shifts downstream when the critical conditions are met.

Within the tested range of conditions, the boundary layer of the arc develops downstream of a turbulent leading-edge separation bubble. In the subcritical regime, the reattached boundary layer relaminarises due to the highly accelerated flow near the leading edge. In contrast, in the transcritical regime the boundary layer is turbulent from inception (i.e. from the reattachment point downstream of the bubble) all the way to trailing-edge separation. Therefore, while on a circular cylinder the force crisis is due to laminar-to-turbulent transition of the boundary layer at transcritical conditions, on the arc it is due to relaminarisation of the boundary layer at subcritical conditions. The force crisis is shown to depend on both the Reynolds number and the angle of attack, and the critical angle of attack varies linearly with the Reynolds number.
The circular arc geometry depends on the camber, the thickness and the leading-edge shapes. The three investigated arcs have sharp leading edges and thickness-to-chord ratios lower than 0.0018 . The comparison with the forces measured by other authors on arcs about twice as thick suggests that the effect of such low thicknesses is negligible. Hence, the results can be generalised to infinitely thin arcs.

Within the range of tested Reynolds numbers, transition occurred in the leading-edge separation bubble, resulting in turbulent reattachment. At Reynolds numbers of 150,000 and 218,000 , which were tested in the towing tank where particle image velocimetry could not be undertaken, it cannot be ruled out that relaminarisation is followed by turbulent transition somewhere further downstream along the arc.

Bearing in mind these limitations, these findings contribute to characterise the critical regimes on circular arcs, and reveal how similar force behaviours to circular cylinders are indeed due to a very different physical mechanism. This is critical to the design of lift and drag control devices. Overall, these results may contribute to the design of thin cambered wings, sails and blades at a transitional Reynolds number, such as the wings of micro aerial vehicles, swept wings in subsonic flight, turbomachinery blades and the sails of autonomous sailing vessels.

\section{ACKNOWLEDGMENTS}

This work received funds from the School of Maritime Science and Engineering of Solent University; the Maritime Trus Fund via the 2018 Research, Knowledge Exchange and Innovation Award; and the Institute of Marine Engineering, Science and Technology via the 2019 Stanley Grey Fellowship.

\section{REFERENCES}

E. V. Laitone, "Aerodynamic lift at Reynolds numbers below 7×104", AIAA Journal 34(9), 1941-1942 (1996)

2 S. Sunada, T. Yasuda, K. Yasuda, and K. Kawachi, "Comparison of wing characteristics at an ultralow Reynolds number", J. Aircraft 39(2), 331-338 (2002) https://doi.org/10.2514/2.2931

3 B. R. Hein, and I. Chopra, "Hover performance of a micro air vehicle: rotor at low Reynolds number", J. Am. Helicopt. Soc. 52(3), 254-262 (2007). https://doi.org/10.4050/JAHS.52.254

4 M. Ramasamy, B. Johnson, and J. G. Leishman, "Understanding the aerodynamic efficiency of a hovering micro-rotor", J. Am. Helicopt. Soc. 53(4), 412-428 (2008) https://doi.org/10.4050/JAHS.53.412

5 D. J. Tritton, "Experiments on the flow past a circular cylinder at low Reynolds numbers", J Fluid Mech. 6(4), 547-567 (1959). https://doi.org/10.1017/S0022112059000829

6 A. Roshko, "Experiments on the flow past a circular cylinder at very high Reynolds number", J. Fluid Mech. 10(3), 345-356 (1961). https://doi.org/10.1017/S0022112061000950

7 G. Eiffel, "Sur la résistance de l'air des sphères dans l'air en mouvement" [On the air drag of spheres in through air], Acad. Sci. 155, 1597 (1912)

8 S. Bloor, "The transition to turbulence in the wake of a circula cylinder", J. Fluid Mech. 19(2), 290-304 (1964). https://doi.org/10.1017/S0022112064000726

9 G. Schewe, "On the force fluctuations acting on a circula cylinder in crossflow from subcritical up to transcritical Reynolds numbers", J. Fluid Mech. 133, 265-285 (1983). https://doi.org/10.1017/S0022112083001913 
10 G. Schewe, "Sensitivity of transition phenomena to small perturbations in flow round a circular cylinder", J. Fluid Mech. 172, 33-46 (1986). https://doi.org/10.1017/S0022112086001635

11 G. Schewe, "Reynolds-number effects in flow around moreor-less bluff bodies". J. Wind Eng. Ind. Aerodyn. 89(14-15), 1267-1289 (2001) https://doi.org/10.1016/S0167-6105(01)00158-1

12 F. W. Schmitz, "Aerodynamik des Flugmodells" [Aerodynamics of the model airplane], Berlin C.J.E. Volckmann Nachf. E (1942)

13 J. D. Tank, B. F. Klose, G. B. Jacobs, and G. R. Spedding, "Flow transitions on a cambered airfoil at moderate Reynolds number", Phys Fluids 33, 093105 (2021) https://doi.org/10.1063/5.0061939

14 P. Bot, M. Rabaud, G. Thomas, A. Lombardi, C. Lebret, "Sharp transition in the lift force of a fluid flowing past nonsymetrical obstacles: evidence for a lift crisis in the drag crisis regime", Phys. Rev. Lett. 117(23), 234501 (2016). https://doi.org/10.1103/PhysRevLett.117.234501

15 S. Nava, P. Bot, J. E. Cater, and S. E. Norris, "Modelling the lift crisis of a cambered plate at 0 degree angle of attack", 20th Australasian Fluid Mechanics Conference, Perth (2016).

16 L. Zhang, and R. K. Agarwal, "Numerical simulation of flow past a circular arc and a truncated circular cylinder in transitional flow", AIAA SciTech Forum, 2018 AIAA Aerospace Sciences Meeting, Kissimmee, Florida (2018).

17 M. M. Zdravkovich, "Conceptual overview of laminar to turbulent flows past smooth and rough circular cylinders", JAWE Wind Engineering 1988(37), 93-102 (1988). https://doi.org/10.5359/jawe.1988.37_93

18 M. M. Zdravkovich, "Flow around circular cylinders: fundamentals", Oxford Science Publications (1997).

19 D. E. Gault, "An investigation at low speed of the flow over a simulated flat plate at small angles of attack using pitot static and hot-wire probes", National Advisory Committee for Aeronautics, Technical Note 3876 (1957).

20 R. A. Wallis, "Boundary layer transition at the leading edge of thin wings and its effect on general nose separation", ICAS Second Congress, Zurich (1960).

21 D. Marsden, R. Simpson, and W. Rainbird, "An investigation into the flow over delta wings at low speeds with leading edge separation", Cranfield: College of Aeronautics, Cranfield Report No. 114. ARC 20, 409 (1958).

22 J. Harvey, "Some measurements on a yawed slender delta wing with leading edge separation", A.R.C. R.\&M. 3160 (1959).

23 T. Ota, Y. Asano, and J. I. Okawa, "Reattachment length and transition of the separated flow over blunt flat plates", JSME 24(192), 941-947 (1981).

https://doi.org/10.1299/jsme1958.24.941

24 P. Bot, "Force variation related to flow pattern changes around a high-camber thin wing", AIAA Journal 58(5), 1906-1912 (2020). https://doi.org/10.2514/1.J058443

25 R. Mukund, P. R. Viswanath, R. Narasimha, A. Prabhu, and J. D. Crouch, "Relaminarisation in highly favourable pressure gradients on a convex surface", J. Fluid Mech. 566, 97-115 (2006). https://doi.org/10.1017/S0022112006002473

26 B. G. J. Thompson, "The prediction of boundary-layer behaviour and profile drag for infinite yawed wings", RAE CP 1308 (1974).

27 D. Arnal, and J. C. Juillen, "Leading-edge contamination and relaminarisation on a swept wing at incidence", In: T. Cebeci (eds), Numerical and Physical Aspects of Aerodynamic
Flows, Springer, Berlinm Germany

(1990) https://doi.org/10.1007/978-3-662-02643-4_25

28 C. P. Van Dam, P. M. H. W. Viggen, L. P. Yip, and R. C. Potter, "Leading edge transition and relaminarisation phenomena on a subsonic high lift system", AIAA Paper 93 3140 (1993). https://doi.org/10.2514/6.1993-3140

29 E. Malkiel, and R. E. Mayle, "Transition in a separation bubble", J. Turbomach. 118 (4), $752-759$ (1996) https://doi.org/10.1115/1.2840931

30 S. J. Collie, P. Jackson, M. Gerritsen, and J. B. Fallow "Twodimensional CFD-based parametric analysis of downwind sail designs", Int. J. Small Craft Tech. (2004) http://doi.org/10.3940/rina.ijsct.2004.b1.19041

31 A. P. D. Wheeler, A. Sofia, and R. J. Miller, "The effect of leading-edge geometry on wake interactions in compressors", J. Turbomach. 131(1), 041013 (2009) https://doi.org/10.1115/1.3104617

32 A. D. Henderson, and G. J. Walker, "Observations of transition phenomena on a controlled diffusion compressor stator with circular arc leading edge", J. Turbomach. 132(3), 031002 (2010). https://doi.org/10.1115/1.3144163

33 S. C. T. Perkins and A. D. Henderson, "Separation and relaminarisation at the circular arc leading edge of a controlled diffusion compressor stator", Proceedings of the ASME Turbo Expo 2012, Copenhagen, Denmark (2012).

34 N. Velychko, "Study of highly cambered aero foil using JR3 sensor", The University of Auckland, Department of Mechanical Engineering (2014).

35 R. G. J. Flay, A. Piard, and P. Bot, "Aerodynamics of a highly cambered circular arc aerofoil: experimental investigations", $4^{\text {th }}$ International Conference on Innovation in High Performance Sailing Yachts, Innov'Sail, Lorient (2017).

36 International Organization for Standardization, "ISO 6344 1:1998 Coated abrasives - Grain size analysis - Part 1: Grain size distribution test", International Organization fo Standardization, Geneva (1998).

37 International Towing Tank Conference, "ITTC Quality System Manual - Recommended Procedures and Guidelines Procedure - Ship Models", $28^{\text {th }}$ International Towing Tank Conference, Wuxi, (2017).

38 J. M. M.-A. Dewavrin, and J.-B. R. G. Souppez, "Experimental investigation into modern hydrofoils-assisted monohulls: how hydrodynamically efficient are they?", Intl. J. Small Craft Tech. 160(2), 111-120 (2018).

https://doi.org/10.3940/rina.ijsct.2018.b2.223

39 International Towing Tank Conference, "ITTC Recommended Procedures - Fresh Water and Seawate Properties", $26^{\text {th }}$ International Towing Tank Conference, Rio de Janeiro (2011)

40 A. Arredondo-Galeana, and I. M. Viola, "The leading-edge vortex of yacht sails", Ocean Eng. 159, 552-562 (2017) https://doi.org/10.1016/j.oceaneng.2018.02.029

41 A. Arredondo-Galeana, "A study of the vortex flows of downwind sails", PhD Thesis, University of Edinburgh, Insitute for Energy Systems (2019)

42 J. P. J. Stevenson, K. P. Nolam, and E. H. J. Walsh, "Particle image velocimetry measurements of induced separation at the leading edge of a plate", J. Fluid Mech. 804, 278-297 (2016). https://doi.org/10.1017/jfm.2016.532

43 E. Baum, B. Peterson, B. Böhm, and A. Dreizler, "On the validation of les applied to internal combustion engine flows: part 1: comprehensive experimental database", Flow Turbulence Combust. 92, 269-297 (2014). https://doi.org/10.1007/s10494-013-9468-6 
44 A. Pope, and J. J. Harper, "Low-speed wind tunnel testing", John Wiley \& Sons Inc, New York (1966).

45 Engineering Sciences Data Unit, "ESDU 80024: Blockage corrections for bluff bodies in confined flows", Engineering Sciences Data Unit, ISBN: 9780856793073 (2006).

46 S. J. Collie, "Application of computational fluid dynamics to two-dimensional downwind sail flows", PhD Thesis, University of Auckland, Departments of Mechanical Engineering and Engineering Science (2006).

47 K. Fujiwara, R. Sriman, and K. Kontis, "Experimental investigations on the sharp leading-edge separation over a flat plate at zero incidence using particle image velocimetry", Exp. Fluids 61, 205 (2020).

48 V. Martin, "Reynolds number and angle of attack effects on a highly cambered thin profile flow topology", MSc Thesis, French Naval Academy Research Institute (IRENav) (2015). https://doi.org/10.1007/s00348-020-03039-w

49 I. M. Viola, and R. G. j. Flay, "Sail aerodynamics: Understanding pressure distributions on upwind sails", Exp. Therm. Flu. Sci. 35(8), pp 1497-1504 (2011) https://doi.org/10.1016/j.expthermflusci.2011.06.009

50 I. M. Viola, A. Arredondo-Galeana, and G. Pisetta, "The force generation mechanism of lifting surfaces with flow separation", Ocean Eng. (239), 109749 (2021). https://doi.org/10.1016/j.oceaneng.2021.109749

51 D. Veerasamy, and C. Atkin, "A rational method for determining intermittency in the transitional boundary layer", Exp. Fluids 61(11), 2020. https://doi.org/10.1007/s00348019-2856-5

52 D. Lee, S. Kawai, T. Nonomura, M. Anyoji, H. Aono, A. Oyama, K. Asai K, and K. Fujii, "Mechanisms of surface pressure distribution within a laminar separation bubble at different Reynolds numbers", Phys. Fluids 24, 85-105 (2015). https://doi.org/10.1063/1.4913500

53 M. Crompton, and R. Barrett, "Investigation of the separation bubble formed behind the sharp leading edge of a flat plate at incidence", Proc. Instn. Mech. Eng. 214(G), 157-176 (2000). https://doi.org/10.1243/0954410001531980

54 L. E. B. Sampaio, A. L. T. Rezende, and A. O. Nieckele, "The challenging case of the turbulent flow around a thin plate wind deflector, and its numerical prediction by LES and RANS models", J. Wind Eng. Ind. Aerodyn. 133, $52-64$ (2014). https://doi.org/10.1016/j.jweia.2014.07.007

55 M. Breuer, "Effect of inflow turbulence on an airfoil flow with laminar separation bubble: an LES study", Flow Turbulence Combust. 101, 443-456 (2018).

https://doi.org/10.1007/s10494-017-9890-2

56 M. Langari, and Z. Yang, "Numerical study of the primary instability in a separated boundary layer transition under elevated free-stream turbulence", Phys. Fluids 25, 074106 (2013). https://doi.org/10.1063/1.4816291

57 R. Narasimha, and K. R. Sreenivasan, "Relaminarisation of fluid flows", Advances in Applied Mechanics 19, 221-309 (1979). https://doi.org/10.1016/S0065-2156(08)70311-9

58 B. E. Launder, "Laminarisation of three-dimensional accelerating boundary layers in a curved rectangularsectioned duct", Int. J. Heat Fluid Flow 13, 124-131 (1964). 